\title{
Lichen planus pigmentosus inversus*
}

Líquen plano pigmentoso invertido

Hugo Rocha Barros
Angelo Sementilli

DOI: http://dx.doi.org/10.1590/abd1806-4841.20132599

\author{
José Roberto Paes de Almeida ${ }^{2}$ \\ Ney Romiti ${ }^{5}$
}

Sandra Lopes Mattos e Dinato ${ }^{3}$

Abstract: Twenty-five year old male patient presenting with asymptomatic brown spots, on cervical, axillary,
inguinal and popliteal regions, for the last nine months. Pathological examination showed hydropic degenera-
tion of the basal layer, pigmentary incontinence and moderate inflammatory lymphocytic infiltrate in the dermis.
Lichen planus pigmentosus inversus is a rare subtype of lichen planus characterized by hyperchromic, asympto-
matic or mildly pruritic macules, measuring from millimeters to centimeters in diameter, with defined borders,
affecting intertriginous areas, most commonly in the axillae and groin of Caucasian patients. It presents unique
lichenoid histology. We report a case with typical clinical features, histology and evolution. Keywords: Axilla; Groin; Lichen planus; Lichenoid eruptions; Skinfold thickness

Resumo: Homem, 25 anos, com manchas acastanhadas, assintomáticas, nas regiões cervicais, axilares, inguinais e poplíteas há nove meses. Anatomopatológico com degeneração hidrópica da basal, incontinência pigmentar e infiltrado inflamatório linfocitário moderado na derme. O líquen plano pigmentoso invertido é um subtipo raro de líquen plano, caracterizado por máculas hipercrômicas, assintomáticas ou discretamente pruriginosas, de milímetros a centímetros de diâmetro, com limites nítidos, nas áreas intertriginosas, sendo mais comum nas flexuras axilares e inguinais de indivíduos de pele clara. Apresenta histologia liquenóide peculiar. Relata-se um caso com clínica, histologia e evolução típicas.

Palavras-chave: Axila; Erupções liquenóides; Líquen plano; Pregas cutâneas; Virilha

\section{INTRODUCTION}

Lichen planus pigmentosus inversus (LPPI) is a pigmentary cutaneous manifestation located on skinfold areas, and considered a rare variant of lichen planus pigmentosus..$^{1-5}$ Approximately 20 cases are reported in the medical literature worldwide. The etiology is unknown, without any causal relation to medications or sun exposure. The pathogenesis appears to be related to a $\mathrm{T}$ lymphocyte-mediated, cytotoxic activity against basal keratinocytes. ${ }^{1,3}$ From the clinical standpoint, this disease is characterized by asymptomatic hyperchromic macules, millimeters to centimeters in diameter, with well-delimited edges, smooth surface and on occasion Wickham striae; located on intertriginous areas, particularly axillae and groins of Caucasian, European-descendant patients. Usually, mucosae, scalp, and palmoplantar areas are not affected by the disease. ${ }^{2-4,6}$ Histologically there is a pattern compatible with lichen planus in regression, with minor or absent hyperkeratosis and hypergranulosis, and even, in some cases, atrophic epidermis. ${ }^{1,3-5}$

Approved by the Advisory Board and accepted for publication on 18.05.2013.

* Work performed at the dermatology clinic at Guilherme Álvaro Hospital - Santos (SP), Brazil.

Conflict of interest: None

Financial funding: None

\footnotetext{
MD, specialist in Internal Medicine by the Brazilian Society of Internal Medicine - Resident on the dermatology program at the Lusíada University Center (UNILUS) - Santos (SP), Brazil.

MD, MSc in dermatology at São Paulo Federal University (UNIFESP) - Assistant Professor of dermatology at the Lusíada University Center (UNILUS) - Santos (SP), Brazil.

MD, PhD in dermatology at the São Paulo University (USP) - Professor of dermatology at the Lusíada University Center (UNILUS) - Santos (SP), Brazil.

MD, PhD in pathology at São Paulo Federal University - Professor of Pathology at the Lusíada University Center (UNILUS) - Santos (SP), Brazil.

MD, PhD in Dermatology - Post-doctorate in dermatology at the Lusíada University Center (UNILUS) - Santos (SP), Brazil.

(ㅇ)2013 by Anais Brasileiros de Dermatologia
} 


\section{CASE REPORT}

A twenty-five year old male patient, brownskinned, informed that for the past 9 months he had noticed the appearance of asymptomatic brown spots, on the cervical region, axillary, inguinal and popliteal folds. He denied the appearance of other cutaneous lesions, pruritus, systemic symptoms, previous diseases or the use of illicit drugs or medications. On examination, we observed hyperchromic, smooth-surfaced macules, with well-delimited edges, measuring from millimeters to centimeters in diameter and often of an oval shape (Figures 1 to 3). There were not other lesions either on skin, nails, scalp, or mucosae, nor signs of lymphadenomegaly.

Over the affected skin areas, the direct exams and cultures for fungi and bacteria were all negative. Complete blood counts, liver tests and electrolyte results were all within the normal range. Hepatitis $C$ serology was negative. Anatomopathological exams of the lesions were performed from distinct samples (right and left axilla), and repeated on a three-month interval with identical characteristics: discreet rectification of epithelial cones in the epidermis, irregular hydropic degeneration on the basal layer, marked pigmentary incontinence with the presence of melanophages on the superficial dermis and light to moderate inflammatory lymphocytic infiltrate surrounding the capillary vessels of the papillary and reticular dermises (Figures 4 and 5).

Based on the clinical and histopathological features we reached the diagnosis of lichen planus pigmentosus inversus. Afterwards, we initiated treatment with systemic corticoid using prednisone $20 \mathrm{mg} /$ day for 30 days, without any therapeutic response. After four months, without any further treatment, the patient presented with a discreet improvement on the cervical and popliteal regions, whilst axillary lesions remained unaltered.
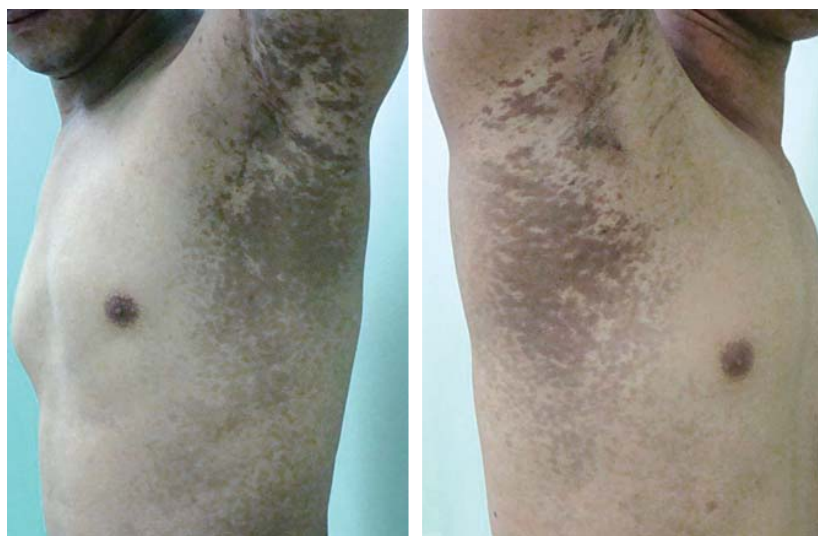

Figure 1: Extensive and confluent hyperchromic macules, with smooth surface and well-marked edges, on the right and left axillae

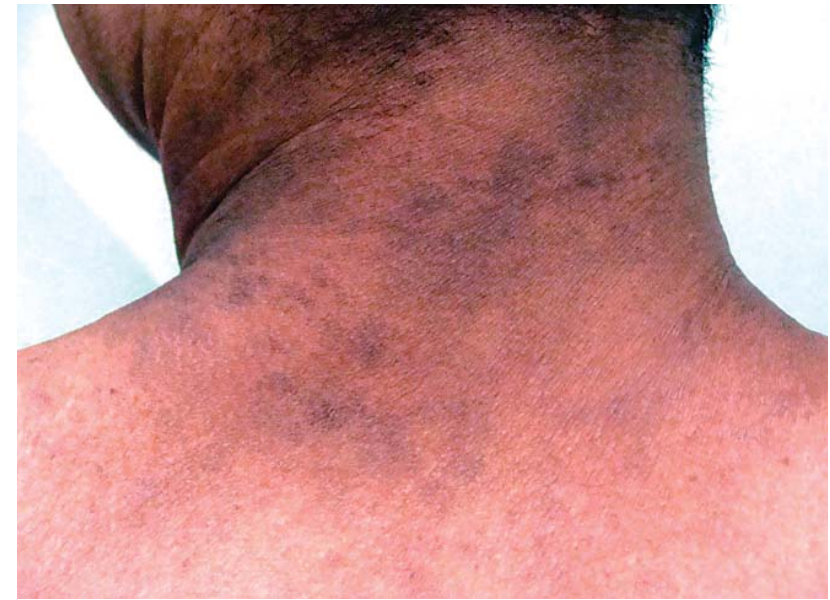

FIGURE 2: Hyperchromic confluent macules on the posterior cervical region

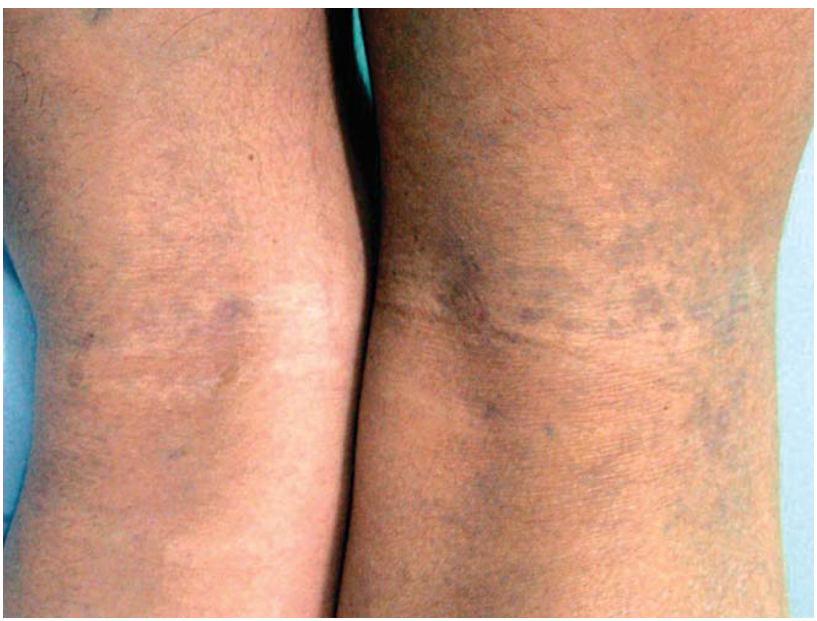

FIGURE 3: Hyperchromic confluent macules on the popliteal area

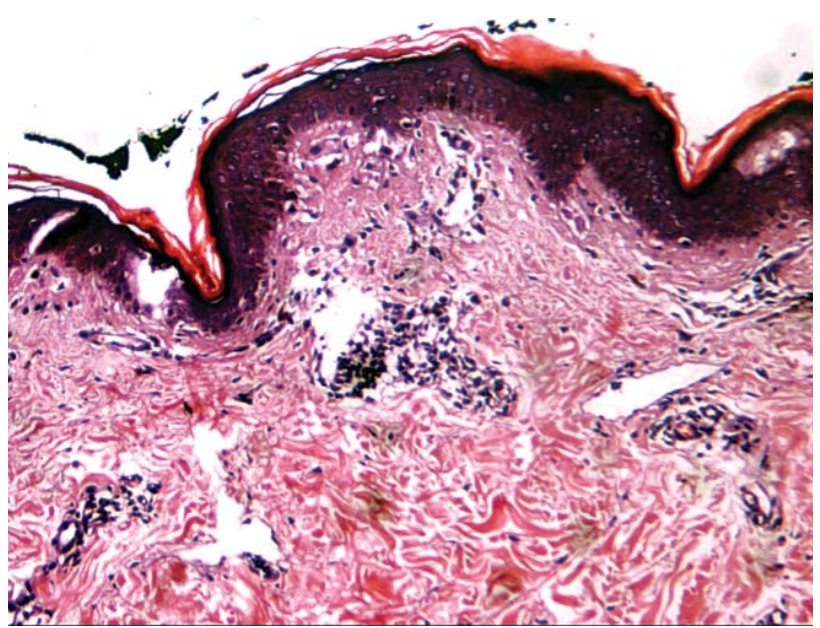

FIGURE 4: Epidermis with hyperkeratotic foci and light perivascular inflammatory mononuclear infiltrate (HE, 200x) 


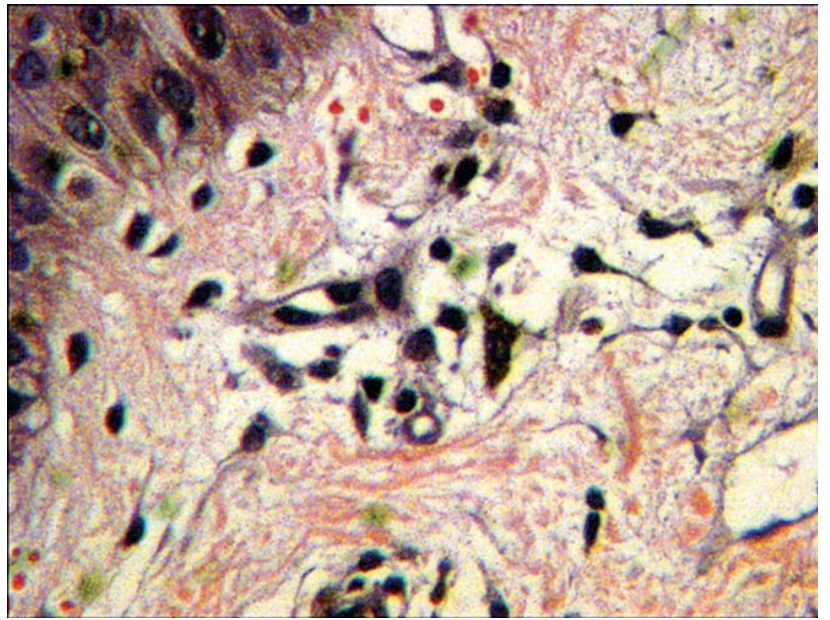

FIGURE 5: Discreet degeneration on the basal layer and pigmentary incontinence (HE, 400x)

\section{DISCUSSION}

The term lichen planus pigmentosus inversus (LPPI) was proposed by Pock et al in 2001, after the report of 7 cases of lichen planus pigmentosus located predominantly on intertriginous areas. ${ }^{3}$ Gaertner and Elstein, in 2012, considered the clinical and histological manifestations of LPPI as distinct from other similar entities, such as lichen planus pigmentosus and erythema dyschromicum perstans (dermatosis ceniciento or ashy dermatosis). ${ }^{1}$

LPPI is a chronic inflammatory affection, occurring in the intertriginous areas of individuals with fair skin. Cases affecting Asian patients have been more frequently reported and until the present there were not any cases reported on the indexed national medical literature..$^{1,3-5}$ In a recent review of 18 cases, eight were men $(44 \%)$ and ten were women $(56 \%)$, with a mean age of 58.8 years ( 25 to 84 years). As to ethnic descent, 11 were white $(61 \%)$ and seven were Asians $(39 \%)$. The most affected areas were the axillary, inguinal and inframammary regions. In seven cases $(39 \%)$, a light pruritus was present, without any other associated symptoms. There was an absence of lesions on scalp, mucosae and nails in all cases reported. ${ }^{5}$

The patient described here is a young adult male (25 years-old), of brown skin, with extensive non-pruriginous clinical features, affecting several areas (axillary, cervical, inguinal and popliteal). Also of notice is the absence of other dermatological and systemic abnormalities. These data are in accordance with the previously reported cases.

The literature shows that the characteristic manifestations of LPPI are hyperchromic macules, usually small, lenticular, with discreet to absent pruritus, affecting intertriginous areas, mainly axillae (affected in $90 \%$ of the reported cases), and also cervical, inguinal and popliteal areas. Larger lesions tend to have a linear or angular configuration, with the longitudinal axis following the cleavage lines. Wickham striae have also been reported. ${ }^{1,-5}$ In a minority of patients, additional lesions with features of lichen planus or lichen planus pigmentosus may be found outside of the flexor surfaces, but they are scarce, accounting for about $10 \%$ of all the area affected. ${ }^{3}$ The association between LPPI and malignant neoplasms remains unconfirmed. ${ }^{1-5}$

The main differential diagnoses are erythema dyschromicum perstans, post-inflammatory hyperpigmentation, figurate erythema, fixed drug eruption and lichen planus pigmentosus. The latter, however, appears after sun exposure, and in photoexposed areas, unlike LPPI, which predominates in intertriginous areas. The most difficult differential diagnosis is with ashy dermatosis, this, however, affects brown skinned patients, with a tropism for the torso and limbs (and not for intertriginous areas) and with erythematous borders on the edges of active lesions. ${ }^{1,3,5-8}$ Microscopically, one can observe a lichen planus in regression. There is epidermic atrophy with irregular hydropic degeneration on the basal layer and an absence of epidermic hyperplasia (usually present on lichen planus). In the superior dermis, there is exuberant pigmentary incontinence, with melanophages and a lichenoid inflammatory infiltrate containing lymphocytes and histiocytes, in a variable pattern, according to the clinical stage of lichenoid regression.

Histopathology, as in the case reported here, revealed marked pigmentary incontinence and discreet lichenoid infiltrate. ${ }^{1,3-5}$ According to Pock et al in 2001, the lichenoid reaction seems to occur within a short period of time and with marked hydropic degeneration of the basal keratinocytes. Similarly to typical lichen planus, there is a compensatory proliferation of those keratinocytes, which do not develop in intertriginous areas.

This disease evolves with a variable clinical course; in general there is a rapid appearance of hyperchromic macules, those being the most frequently found lesions and not the traditional papules ${ }^{3-9}$ Some cases will resolve in some weeks without therapy, while others may persist for years. ${ }^{1-5,7,9}$ Topical treatments with tacrolimus and high-potency corticoids had variable success (such as a decline in pigmentation), in isolated cases. ${ }^{1,7-9}$ In the case reported here, there was a spontaneous partial involution (lightening of lesions) after four months of follow-up; initially there was no clinical improvement, even with corticoid therapy. $\square$ 


\section{REFERENCES}

1. Gaertner E, Elstein W. Lichen planus pigmentosus-inversus: Case report and review of an unusual entity. Dermatol Online J. 2012;18:11.

2. Breathnach SM, Black MM. Lichen Planus and Lichenoid Disorders. In: Champion RH, Burton JL, Burns DA, Breathnach SM, editors. Rook/ Wilkinson/ Ebling. Textbook of Dermatology.7th ed. Oxford: Blackwell Science; p.2102.

3. Pock L, Jelínková L, Drlík L, Abrhámová S, Vojtechovská S, Sezemská D, et al. Lichen planus pigmentosus-inversus. J Eur Acad Dermatol Venereol. 2001;15:4524.

4. Noh TW, Park SH, Hong KC, Baek JH, Lee UH, Park HS, et al. Lichen Planus Pigmentosus-inversus. Korean J Dermatol. 2011;49:370-3.

5. Jung YJ, Lee YH, Lee SY, Lee WS. A case of lichen planus pigmentosus-inversus in a Korean patient. Ann Dermatol. 2011;23:61-3.

6. Kashima A, Tajiri A, Yamashita A, Asada Y, Setoyama M. Two Japanese cases of lichen planus pigmentosus-inversus. Int J Dermatol. 2007;46:740-2.

7. Ohshima N, Shirai A, Saito I, Asahina A. Lichen planus pigmentosus-inversus occurring extensively in multiple intertriginous areas. J Dermatol. 2012;39:412-4.

8. Cherobin AC, Oliveira FO, Baeta IG, Vale EC. Case for diagnosis. Ashy dermatosis. An Bras Dermatol. 2012;87:151-2.

9. Villaverde RR, Gutierrez MG, Cano DS, Salvago DM. Liquen plano pigmentoso inverso: fácil de diagnosticar, difícil de tratar (Lichen planus pigmentosus inversus: easy to diagnose, difficult to treat). Piel. 2011;26, December 2011:538-40.
MAILING ADDRESS:

Hugo Rocha Barros

Rua Dr. Oswaldo Cruz, 197 - Boqueirão

11045-101 - Santos - SP

Brazil

E-mail: hugobarroshb@yahoo.com.br

How to cite this article: Barros HR, Almeida JRP, Dinato SLM, Sementilli A, Romiti N. Lichen planus pigmentosus inversus. An Bras Dermatol. 2013;88(6 Suppl 1):S146-9. 